sion of nonexistence of the appendix. There are also cases on record of the entire absence of the organ; but in these cases either the patient was operated on for some other disease, or investigation was made postmortem.

\section{A SIMPLE METHOD OF LOCALIZATION OF FOREIGN BODIES}

J. S. Young, M.D., Lieutenant, Hospttal 22, B. E. F., France Late Radiologist, Washington University Medical School, St. Louis

One of the most important tasks in hospitals here is the localization of foreign bodies. Many methods are being used. The one which I am employing is to my mind the most simple and the most accurate. It involves the use of a small apparatus with an aluminum base which rests underneath the part of the patient which contains the foreign body, and an upright standard which rests on the broad end of the aluminum base. This standard has two adjustable cuffs through which pass two rods, an upper and a lower. The upper rod has a loop on its end; the lower, a small metallic ball. These rods are adjustable in two directions, and are secured by two set screws
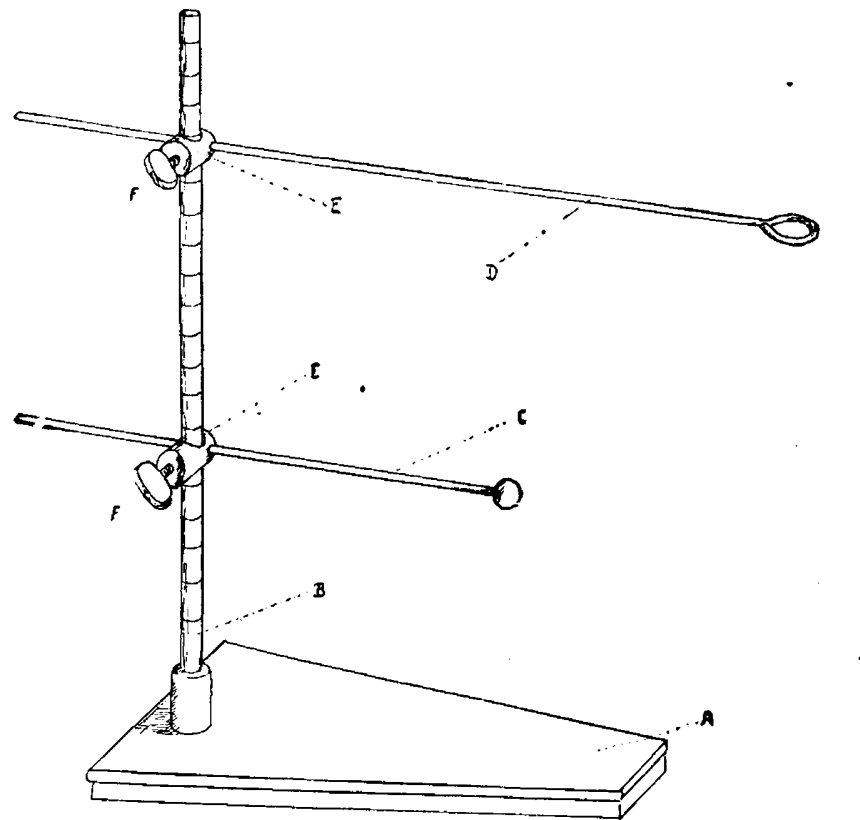

Apparatus for localization of foreign bodies: $A$, aluminum base; $B$, standard; $C$, lower adjustable rod with ball; $D$, upper adjustable rod witl ring; $E$, lower cuff (adjustable); E, upper cuff (adjustable); $F$, lower set screw; $F$, upper set screw.

A patient is placed on the aluminum base (the tube, of course, being underneath the table), the foreign body is located, and by the central rays the loop is placed directly over the foreign body. After the loop on the upper rod has been placed close to the skin so that there will be no motion, the diaphragm is opened and the tube moved to and fro. The ball is then adjusted so that it moves in the same plane with the foreign body. The foreign body is thus localized in two directions, the ball locating it at the base line and the loop locating it in the upper plane.

There may be others who are using this method without the aluminum base on which the patient rests, but there is always a chance of slight displacement unless the localizer is held in position by the patient.

With this method one can, of course, make mistakes. But it is perfectly simple and is absolutely correct if the operator is careful, first, in posing his patient, and secondly, in observing the foreign body and ball until he is sure that they move in the same plane; otherwise he will find that there is a variation of from half an incl to 2 inches in the lower plane of his localization.

\section{Military Medicine and Surgery}

\section{SOME OF THE ACCOMPLISHMENTS OF ITALIAN MEDICAL MEN IN THE WAR}

VICTOR G. HEISER, M.D.

Member, American Red Cross Commission to Italy NEW YORK

It is generally understood that the Italian army at the present time consists of at least 4,000,000 men, and that the number of hospital beds is approximately $1,000,000$. Just what it means in two years to expand a country's hospital service to these huge proportions can be better appreciated when it is recalled that in the entire United States, with a population almost three times as great as that of Italy, there are only 300,000 beds. Yet in spite of this vast achievement, the work accomplished by the Italian medical profession since the beginning of the war has attracted to itself but little attention in this country. The reasons for this are obvious. While probably none of the Allies who are fighting in Europe have received less aid other than financial help from ontside their own borders, the medical men of Italy almost invariably were loath to speak of their achievements. There was no boastfulness anywhere. It is charateristic of the Italian medical service to achieve results and then perhaps talk about them. Nowhere did we hear of what the medical service was going to do. It was only of the things they had done of which they could be indticed to speak. The equipment necessary for preventing disease and for the care of the sick and wounded has been provided almost entirely in Italy. In many instances establishments for the production of hospital and medical supplies did not exist at the outbreak of the war, and had to be created. Large institutions for the reeducation of the injured, that will compare favorably 'with the best, are in full operation. Hospitals rendering excellent service exist near the front-line trenches. New types of hospital construction have been evolved. Mobile hospitals of 100 bed capacity, which can be taken down and transferred 75 miles and set up and put in service again within twenty-four hours, are in use ; the entire equip-. ment, including the hospital furniture, instruments, operating room appliances, and roentgen-ray plant, is transported on five camions (motor trucks) and three touring cars. New operations, particularly in dental and lung surgery, new instruments and devices without number, have been developed. The following statement, although very incomplete, may convey some idea of what had been accomplished by the Italian medical profession prior to Oct. 1, 1917.

\section{ORGANIZATION}

The Italian medical service is presided over by an official who has his office with the minister for war at Rome. The service, however, is not so highly centralized as is the case in this country. There is a chief medical officer, common to all the armies, who has his headquarters near the front, at a point which is the principal center for the storage and distribution 
of supplies, not only for the medical department, but also for the entire army. Representatives of the quartermaster's and commissary departments, of the signal corps, ammunition department, Red Cross, and other branches of the army, are located there. They dine together in a common mess hall and have ample opportunity for cooperation. Under the chief medical officer there is stationed with each army a principal medical officer who has almost determining powers in directing the medical work pertaining to the army with which he is stationed.

The care of the wounded at the front, as well as throughout Italy, is undertaken jointly by the Italian Red Cross and the Sanitare Militare, or Army Medical Service, medical aid being rendered through the following seven classes of agencies, which cooperate in passing back the wounded with a remarkable degree of efficiency, and may be considered in the order of their relative distance from the front-line trenches.

1. The Posti Medicazione.-These are the most advanced dressing stations for emergency services, and are located usually in dugouts in trenches very close to the front.

2. The Sezione Sanita-From 1 to 2 kilometers behind the front, usually at a point which can be reached by an ambulance, are the Sezione Sanita, or dispensaries. They are more fully equipped than the preceding.

3. Ambulancia di Montagna.-These are located from 2 to 5 kilometers behind the front, and are the most advanced point reached by the Italian Red Cross.

4. The Stazione di Sanita.-These are somewhat larger and better equipped than the preceding. Tetanus antitoxin is usually given here.

5. The Ospedale di Campo, or Ficld Hospitals.These are located in convenient and accessible points somewhat farther back. At the outset of the war these were of 50 bed capacity, but experience soon showed that it was frequently necessary that they be of 500 bed capacity. They are now also used as Smistamento, or distributing centers, at which patients are classified and sent to the various special hospitals.

6. Ospcdale di Tappa.-These are base hospitals, and may be located several hundred kilometers behind the lines. They are usually grouped, so that in one village or town or area there may be a bed capacity varying from 20,000 to 40,000 .

7. Ospedale di Reservo.-These hospitals are institutions or other large buildings located throughout the cities of Italy which have been made available for the reception of soldiers.

The whole question of handling the wounded is still in a transitional state. Many hospitals, however, have been actually brought near the front-line trenches.

For each army there are a number of large quarantine or disinfecting stations, equipped for the treatment and detention of soldiers that have come from areas in which dangerous communicable diseases have prevailed, as, for instance, cholera, malaria, dysentery and typhoid. These stations are provided with steam disinfecting apparatus or sulphur dioxid chambers, or other means for disinfecting clothing and equipment. Special effort is made to sterilize textiles that have become infected, and particularly those that may have become infested with body lice or their eggs. Every patient, before being admitted to one of the general hospitals, is detained at a quarantine station for a sufficient time to permit several microscopic examinations of the stool. All prisoners, likewise, are passed through stations of this kind.

\section{HOSPITALS}

Construction.-The hospital accommodation afforded by the Italian Red Cross consists largely of converted tourist hotels, schools and other large buildings that could be adapted to the purpose. The hospitals provided by the medical service of the army consist of existing army hospitals, many of which have been expanded, converted military buildings, or entirely new buildings erected for hospital purposes. The latter are usually one-story pavilions about 14 feet high, 18 feet wide, and of any desired length, constructed of angle iron placed on 6 foot centers, with the intervening space filled in with hollow tile. The tile resembles that used in fireproof construction in this country. The roofs also are of tile. Buildings of this type can be rapidly constructed, and hundreds of beds can be provided in a week or two. Over the course of a year or more, they are much cheaper than tentage. They are cool in summer and can be kept warm in winter. It is noteworthy that one seldom sees patients cared for in tents in Italy.

The decreased use of cavalry in this war has made available large numbers of cavalry barracks. These, when renovated, lend themselves to hospital purposes. At Udine, for instance, one of the cavalry barracks has been made into a single hospital ward with 300 beds. The proportions of this ward are immense. From one end of the room it is almost impossible to see a bed located at the other.

Hospital Locations.-Hospitals are being located nearer and nearer the front, as it has been deemed advisable to risk the occasional danger from shells, in view of the great advantage in having immediate treatment available for the injured. One finds these hospitals in most unusual positions. It was a novel experience to be taken 30 or 40 feet underground, and there, at a point directly over which a battle was raging, to see the regular hospital routine going on in good operating rooms supplied with artificial ventilation and modern hospital furniture, and, in general, admirably adapted to the purpose. To go to the other extreme. at an elevation of 6,000 feet in the Dolomites, we came on a hospital of 30 bed capacity hewn out of the side of a cliff. The two sides and back wall were of stone, and the mountain range at this point was so narrow that through a hole bored in the back wall of the hospital it was possible to look into the Austrian trenches on the other side of the mountain. This hospital may be said to be on the front-line trenches. The wounded that were able to travel after receiving emergency treatment were sent to the rail head on the marvelous teleferica, which often go from mountain-top to mountain-top over chasms thousands of feet deep.

Hospital Specialization.-Specializing has been carried to a high degree. For instance, at Udine we saw 1,500 fracture patients in a single hospital. At other hospitals we saw under treatment only patients with gunshot wounds of the chest. One hospital had 70,000 
admissions during the month of August, which corresponded to a period of active offensive operations. Some of the hospitals are so large that a motor car is required to visit the various buildings.

Great progress has been made in developing the technic. We were told, for instance, that at the hospital in charge of Dr. Bastanelli, Professor Morelli has invented an improved aspirator for draining fluid from the chest. Pressure within and without the lungs can be accurately read on a gage, and through the development of special technic, which among other things permits the lungs to remain collapsed during definite periods, he has been able to produce some startling results in connection with lung surgery. Professor Morelli informed us that he had recently completed 100 cases with no mortality. He believed it to be entirely feasible to keep the mortality well under 5 per cent. in all gunshot wounds of the chest.

Roentgen-Ray Apparatus.-At the time Italy went to war few factories existed for the production of hospital and medical supplies. There was, for instance, scarcely a roentgen-ray apparatus in the country that had not been manufactured in Germany. At present, practically every hospital throughout Italy has one or more roentgen-ray machines, all manufactured in Italy. Not only is the apparatus as good as that formerly imported, but many competent observers believe it to be far superior.

\section{TRANSPORTATION}

Ambulance Service.-A remarkably efficient ambulance service has been established. With the exception of a few cars furnished through the British Red Cross, all of the ambulances have been supplied by the Italian Red Cross of the Italian government. Owing to the mountainous character of the service required, heavier cars have been found to be most practical. During active engagement the empty ambulances going to the front carry many additional stretchers. These are filled and placed in the empty camions that have taken ammunition or other supplies to the front. As a modern war is largely a problem in transportation. this reduces the number of vehicles, prevents congestion of the roads, and affords prompt service for returning the wounded from the most advanced points at the front.

Hospital Trains.-The smooth organization of the hospital train service was one of the most striking features that we saw in Italy. Both the Italian Red Cross and the Army Medical Service provide such trains. There is, indeed, considerable rivalry between these two organizations as to which can furnish the most prompt and efficient evacuation. In a number of instances we saw a train back into a side track next to a hospital, take on board fully 350 wounded, and in less than thirty minutes proceed on its way. There was no confusion, and everything seemed to work with clocklike precision.

\section{NEW INVENTIONS}

One is particularly impressed by the large amount of new apparatus that has been invented. Formerly Zander or similar apparatus mostly came from Germany. Not only are all these now manufactured in Italy, but a large number of new machines have been invented to meet the needs of war cripples. We saw an ingenious pneumatic tourniquet, new apparatus for jaw surgery, improvements in artificial limbs, and many other things too numerous to mention.

Reeducation Institutions.-The Rizzoli Institute in Bologna, created many years before the war, had considerable distinction for its prosthetic appliances and methods of reeducation for lost functions. Almost unbelievable progress in these directions has been made. The Regina Margherita Hospital, or institute for physical reeducation, in Rome, will compare favorably with the best of similar institutions anywhere. This institution has a capacity of 1,200 patients. Of these, 700 are in the physical therapy division. About 600 patients are discharged per month. Some of the passive exercise machines that have been developed are very ingenious. Great stress is laid on specialized forms of physical drill for rehabilitating nerve function. We were shown some truly remarkable results in this direction. The Villa Fiore, which belongs to the American Academy in Rome, has been set aside as an institute for mutilated soldiers. It is directed by Dr. Guali, who has devised most excellent improvements in artificial limbs. It is said that at the outset of the war practically all the limbs had to be purchased in America, but that now almost all are manufactured in Italy, at a great saving in cost. Dr. Guali has invented likewise an ingenious apparatus for registering the pressure of the artificial foot. This apparatus enables him so to modify the limb construction as to bring the pressure to bear similarly to that of the human foot. Certainly some of his results were most striking. At the Rizzoli Institute, in Milan, we saw a soldier who had been blinded in both eyes and had lost both hands, yet who, by the use of an apparatus devised especially for him, was able to use a knife, fork and spoon. At other institutions, after the lost function has been partially restored, a trade suitable to the conditicn of the individual patient is taught. Typewriting, printing, wood carving, lathe work, tinsmithing, basket making, and even primary education, are taught at these various places.

\section{QUARANTINE STATIONS}

In addition to the quarantine stations heretofore mentioned as being located in northern Italy directly in connection with the various hospitals at the front, there are in southern Italy huge quarantine stations which for size will probably long hold world records. Equipment for steam and sulphur fumigation, as well as detention barracks, have been provided. For instance, the French, in order to take care of the soldiers returning from the Saloniki and eastern fronts, have in southern Italy built a quarantine station for 40.000 persons. The British constructed a station for 20,000 soldiers for the same purpose. At these stations careful examinations are made for cholera, typhoid and dysentery carriers. Blood examinations also are made in order to detect malaria. Soldiers found infected are treated before being allowed to return to Great Britain or France. Italy has established huge stations for the return of her soldiers from Saloniki and Albania. When it is stated that over 100,000 malaria patients have been invalided back, the importance of these huge quarantine stations is at once manifest. 


\section{LABORATORIES}

Laboratory work on a gigantic scale, and especially on the preventive side, has become an intimate part of the medical system in the present war. The examination of the stools for cholera, typhoid and dysentery has entailed an enormous amount of work. With the exception of the cholera imported into Italy at the beginning of the war through Austrian prisoners, that disease has not since made its appearance. Yet cholera carriers are constantly detected. This gives one an idea of the wonderful protection afforded by a modern health service.

\section{TUBERCULOSIS}

Considering the size of the Italian army, a comparatively small amount of tuberculosis has been encountered. It is stated that about 5,000 cases appeared among the 4,000,000 troops. However, it is said that more than 30,000 tuberculous Italian prisoners had been returned from Austria. The care of these patients is now receiving much earnest attention. Almost from the beginning roentgen-ray diagnosis was used in the detection of incipient tuberculosis. This form of diagnosis has now become a routine procedure. New recruits are carefully examined before being admitted to the army, and as rapidly as facilities permit, those suspected of being infected are examined with the roentgen ray.

\section{RECLAMATION}

Among other activities with which the medical service is associated is an active reclamation department. The variety and quantity of articles removed from a modern battlefield is almost unbelievable; it includes shoes, clothing, gas masks, first-aid packages, brass, shells, parts of guns, motor trucks, and almost every other conceivable thing. As soon as practicable after a battle, all this paraphernalia, or as much of it as possible, is collected from the field and taken to a central depot. Here it is sorted and sent to the varions factories for repairs. Gas masks, for instance, are sent to a gas-mask repair factory, where the necessary mending is done and the masks reissued. Shoes are disinfected, cleaned and reissued. If in need of cobbling, two pairs of shoes are often made into one. The same obtains with regard to clothing. There are huge disinfecting plants and laundries in connection with these reclamation stations, for the treatment of articles for personal use. Most of the workers in these establishments are women, many of whom are recruited from among the fallen classes.

\section{FIRELESS COOKERS}

One of the striking features in connection with the provision of suitable food for the soldiers in the frontline trenches is the very general employment of huge fireless cookers. This enables the food to be prepared in permanent kitchens well behind the lines, and assures to the soldier absolutely hot meals, no matter how advanced the position in which he finds himself. Huge shops for repairing and retinning these cookers form part of the system.

\section{PRISON CAMPS}

The prison camps at the front consist of barbed wire enclosures with good tents and excellent cooking arrangements. They are divided into three sections. The first is the reception enclosure in which the prisoners are bathed and their clothing disinfected. They are then passed into the second enclosure, where stool specimens are taken for cholera, dysentery and typhoid. After three days' detention in the second enclosure, those whose stools are negative are sent into the third, where they remain perhaps several weeks until arrangements can be made to transter them to permanent locations in the interior. For the officers, houses of a semipermanent character are provided. One is greatly impressed by the kindliness and consideration that are shown to the prisoners of all classes. The food is the same as given to the Italian officer or soldier of corresponding grade. No work is required of officers.

\section{VENEREAL DISEASE}

No actual official records dealing with venereal disease in the army were available. At the front, however, in each army there are special hospitals for the treatment of these patients. The officers and men are not permitted to associate with any women that are not under governmental supervision. The medical officers stated that venereal disease had been reduced to almost negligible proportions.

\section{MEDICAL SCHOOL AT THE FRONT}

Among many other novelties introduced by the Italian medical service is the establishment of a complete medical school near the front-line trenches. The character of the fighting up to the present winter has made this possible. From the beginning of the war to the autumn of 1917 , practically all of the active military work was done between April and November. During the remaining months when the army was comparatively inactive, all the medical students that were serving in the hospital corps or other branches were ordered to San Giorgio di Nogaro, at which point professors from the various medical schools who are in the army also assembled. These professors were assigned to look after the sick in the vicinity of the school. This enabled them to use the clinical material for the benefit of the students. The buildings were mostly of temporary construction, but well adapted to the purpose. Enormous collections of bones and pathologic material generally, which had accumulated as a result of the war, were assembled here.

\section{EFFICIENCY}

Finally, it may be stated that we were much impressed by the excellent care given to the wounded, and the spirit of service manifested by the medical officers. They were on duty early and late, never sparing themselves, quick to meet emergent needs, and through it all a wonderful fellowship and mutual helpfulness prevailed. ${ }^{x}$

61 Broadway.

1. Note.-The American Red Cross Commission to Italy was composed of George F. Baker, Jr., John Morron, Nicholas F. Brady, Dr. Thomas W. Huntington and Dr. Victor G. Heiser. It sailed July 28, 1917, and returned to this country Oct. 22,1917 . After visiting institutions in England and France connected with the war, the commission was given unusual facilities for visiting the French and British fronts in France. It then spent five weeks in Italy studying the conditions to determine how the American Red Cross could render the most efficient aid in Italy. Several weeks were spent at the Italian front. Later visits were made to practically all the centers in Italy and Sicily at which the wounded were cared for. These extended visits enabled the members to gain personal first hand information and to form an idea of the value of the work of the Italians, compared to that seen on the French and British fronts 